\title{
3 Research Square

\section{Clinical Assessment of Integrated Management of Childhood Illnesses (Imci) Given by Professionals Trained Between 2012 and 2015 in Colombia: A Cross-Sectional Study}

Jovana Alexandra Ocampo Cañas ( $\nabla$ ja.ocampo@uniandes.edu.co )

Universidad de Los Andes

Andrés Mauricio García Sierra

Universidad de Los Andes

Yaira Yohanna Pardo Mora

National University of Colombia

Diana Sofía Rios Oliveros

Universidad de Los Andes

Álvaro José Ayala Galvis

Universidad de Los Andes

Luis Jorge Hernández Flórez

Universidad de Los Andes

Jhon Sebastián Patiño Rueda

Universidad de Los Andes

Research Article

Keywords: Integrated Management of Childhood IIInesses, Physicians, Normal Growth and Development, Vaccines and Immunization

Posted Date: April 15th, 2021

DOI: https://doi.org/10.21203/rs.3.rs-401955/v1

License: (c) (1) This work is licensed under a Creative Commons Attribution 4.0 International License.

Read Full License 


\section{Abstract \\ Background}

In Colombia, official statistics indicate that infant mortality by 2020 would reach 7.22 per thousand live births. Prevalent and preventable diseases represent $70 \%$ of total infant mortality, so strategies such as Integrated Management of Childhood Illnesses (IMCI) are still relevant for the country. This research seeks to establish whether the professionals trained in IMCI between 2011 and 2015 apply the strategy in the prevention and care of children under 5 years of age.

\section{Methods}

A cross-sectional study was carried out in general practitioners, nurses and pediatricians who had some level of training in the IMCl strategy between 2012 and 2015. A survey based on the basic competences established in the framework of the IMCl strategy was used: evaluate, classify, and treat and, in addition, the basic care registry component was incorporated.

\section{Results}

Skills in the IMCI Strategy were observed in 259 consultations for children. 229 children were between 2 months and 5 years old, 30 children were between 0 and 2 months old ( $84.4 \%$ vs $11.6 \%$, respectively). $51.4 \%$ of the evaluations were carried out in the Public Health Service Provider Institutions (HPIs) compared to $48.6 \%(126 / 259)$ in the private HPI. In children from 0 to 2 months, $92 \%$ of general practitioners, $82.58 \%$ of nurses, and $59.39 \%$ of pediatricians correctly assessed danger signs. In children from 2 months to 5 years, the health professional who best evaluated the danger signs was the pediatrician with a $70 \%$ correct evaluation, followed by nurses and general practitioners with a $65 \%$ correct evaluation.

\section{Conclusions}

Pediatricians were shown to perform better on the IMCl strategy in children 2 to 5 years of age. However, in the 0-2-month age group, general practitioners and nurses outperformed pediatricians on the IMCI strategy

\section{Background}

Colombia has made significant progress in reducing infant mortality and increasing life expectancy for children, according to the report on Health Situation Analysis (ASIS, by the acronym in Spanish) (1). Despite the achievements of the last decade, acute respiratory infection (ARI) and acute diarrheal disease (ADD) in children under five continue to be a public health problem (2). They occupy the first places of 
morbidity and mortality in this population group. This serves to create a general context of the child health situation in Colombia and to demonstrate the need for strategies to meet the needs of comprehensive care $(3,4)$. These strategies should be addressed and understood as the set of actions for health promotion, prevention, overcoming, recovery and mitigation of health risks or damage (5)

The Integrate Management for Childhood IIIness (IMCl) strategy is an integrated approach to child health that focuses on the overall well-being of the child in his or her lifetime $(6,7)$. It aims to reduce mortality, morbidity, and disability in children up to the age of five. It seeks to ensure the human, social and material conditions to ensure the promotion and empowerment of the integral development of children, from preconception, conception, neonatal period, breastfeeding and childhood in the different environments in which they develop (8). The clinical component of the strategy provides health personnel with a set of practical tools such as assessment, classification, and treatment tables for children under five and related training materials (known as the Procedure Chart and the Clinical IMCI book) (9).

The following study aims to carry out an analysis of the comprehensiveness of health care for children under 5 years of age in service-providing institutions by professionals trained in the clinical component of the IMCl strategy between 2012 and 2015. The processes evaluated to the health professionals trained for the strategy were: the registration of care, the evaluation of danger signs, its classification and treatment.

\section{Methods}

A cross-sectional analytical observational study was conducted. Sixteen municipalities (Aguadas, Apartadó, Bogotá, Bucaramanga, Calarcá, Cali, Cartagena, Floridablanca, Ibagué, Manizales, Medellín, Neiva, Pasto, Quimbaya, Riohacha, and Tunja) were selected by simple random sampling. In which the sample size of general physicians, nurses, and pediatricians was 189 after reviewing records of 14.363 health professionals who had some level of training in the IMCl strategy between 2012 and 2015 (was filtered by type of professional, in this case; nursing, medicine, and pediatrics and the figure was reduced to 4.430$)$.

For the collection of information, a survey was used based on the core competencies established under the IMCl strategy. In addition, the basic care registry component proposed by the Pan American Health Organization was incorporated (9). Informed consent was obtained from the health professionals for the conduct of the surveys.

The evaluation was carried out in the two age groups proposed by the $\mathrm{IMCl}$ strategy. These groups are 0 to 2 months old and 2 months to 5 years old. In the 2-month group, the ability of health personnel to assess and classify skills was assessed. The evaluation competence included the components of basic registration, signs of severity, ADD, growth and nutrition, development, vaccination, and abuse.

For children aged 2 months to 5 years, the competencies evaluated included: an examination of danger signs, ADD, febrile syndrome, otalgia, odynophagia, development, growth, vaccination, the possibility of 
abuse, Human Immunodeficiency Virus (HIV), tuberculosis, epilepsy, and cancer.

A descriptive analysis of the data was made to find the percentages with respect to the correct evaluation of the different sections, previously described, of the IMCl strategy.

\section{Results}

The evaluation of the skills for the comprehensive care of children under five years of age was carried out by observing the care provided by professionals to 259 children and under five years old, 84.4 per cent $(229 / 259)$ children between 2 months and 5 years of age, the remaining 11.6 per cent (30/259) children between 0 and 2 months. 95.4 per cent (247/259) of the children assessed were in urban areas. $51.4 \%$ (133/259) were cared for in Public Health Service Providers Institutions (HPIs) compared to $48.6 \%$ $(126 / 259)$ in private HPIs.

By level of care, $72.6 \%$ (188/259) were assessed at the first level, $16.6 \%(43 / 259)$ at the second level, and $10.8 \%(28 / 259)$ at the third level. Seventy per cent of the children were assessed in the outpatient service, $8.9 \%$ in the emergency department and for the remaining $20.5 \%$ the care service was not specified (Table 1).

Table 1

Characteristics of $\mathrm{IMCl}$ care attention

\begin{tabular}{|llll|}
\hline $\begin{array}{l}\text { Evaluated by general medicine, nursing, and } \\
\text { pediatrics }\end{array}$ & 0 to 2 months & $\begin{array}{l}\text { 2 months to } \mathbf{5} \\
\text { years }\end{array}$ & \\
\hline Attention area & $30(11.6 \%)$ & $229(84.4 \%)$ & \\
\hline Health providing institutions & Urban areas & Rural zones & \\
\hline & $247(95.4 \%)$ & $12(4.6 \%)$ & \\
\hline Level of attention & State HPI* & Private HPI & \\
\hline Service & $133(51.4 \%)$ & $126(48.6 \%)$ & Third level \\
\hline & First level & Second level & Not \\
\hline & $188(72.6 \%)$ & $43(16.6 \%)$ & specified \\
\hline * Health Provider Institutions & Outpatient & Emergency & $53(20.5 \%)$ \\
\hline
\end{tabular}

Results: 0 to 2 Months

- Basic registration 
The health professionals evaluated fully recorded the basic data on the reason for the consultation, the child's age, and the pathological history, and took appropriate height and weight. Concerning the vital sign's registry and cephalic perimeter, the temperature is the least evaluated sign in the two-month-old boys/girls evaluated, and the cephalic perimeter was evaluated in $98.9 \%$ of the cases. The results by professional profile show that $100 \%$ complete registration of basic data, the reason for consultation, age of the child, and pathological history.

\section{- Danger signs}

The profile that most evaluated signs of local infection and serious disease is the general physicians; followed by nurses and pediatricians $(92 \%, 82.58 \%, 59.39 \%$, respectively).

The danger sign that was most evaluated by doctors, nurses, and pediatricians was purulent discharge from the navel, eyes, or ears (93.30\%), followed by the presence of vomiting or difficulty breathing (92.03\% each). The danger signs that were least evaluated were: the presence of seizures $(46.23 \%)$ and the sensation of cold or heat in children (50.30\%).

\section{- Acute diarrheal disease}

In $90.3 \%$ of the cases evaluated, health professionals asked the mother or caregiver if she/he had diarrhea. Only $0.4 \%$ asked about the duration of diarrhea.

\section{- Growth and feeding practices}

All the professionals inquired about whether the baby is fed with breast milk and determined its weight and height. The greatest gap occurred in the investigation for exclusive breastfeeding and the breastfeeding evaluation with $61.6 \%$ and $79.3 \%$, respectively.

$100 \%$ of the two-month-old boys/girls rated by the nurse were evaluated for growth and feeding; followed by the general physician with the evaluation of these aspects in more than $85 \%$ of the cases.

\section{- Development}

In $99.6 \%$ of cases, the mother or caregiver was asked how long the pregnancy lasted and how the delivery was. More than $35 \%$ of health professionals did not assess the cephalic perimeter, with pediatricians who omitted most the measurement.

\section{- Vaccination}

In $96.7 \%$ of the cases, health professionals did not verify a vaccination history for age. Pediatricians only did it in $0.8 \%$ and general physicians in $7.4 \%$.

\section{- Abuse}

In general, physical abuse, sexual abuse, neglect, and abandonment are under verification. Noncompliance is higher than $44 \%$, and pediatricians are the ones who investigate the least for this cause, with a scarce $26 \%$. 


\section{- Competence to Classify}

Following the framework of the IMCI strategy, the results of classification of signs of very serious illness, diarrhea, growth, development, and possibility of abuse, in general, professionals correctly classify the mentioned aspects in about $98 \%$ of the children evaluated, being the nurses who fulfill in $100 \%$ of the cases as included in the table of $\mathrm{IMCl}$ procedures.

\section{Results: 2 months to 5 years}

\section{- Basic registration}

The health professionals evaluated fully recorded the basic data on the reason for consultation, the child's age, and pathological history, and took an adequate measurement of height and weight in more than $85 \%$ of the cases.

Regarding the vital sign's registry and cephalic perimeter, around $40 \%$ of the evaluated professionals did not assess or record these data. Pediatricians have the best results in vital signs and cephalic perimeter (Table 2)

Table 2

Percentage of basic registration by general physicians, nurses, and pediatricians

\begin{tabular}{|llll|}
\hline & $\begin{array}{l}\text { Nurses \% } \\
(\mathbf{N}=\mathbf{4 2})\end{array}$ & $\begin{array}{l}\text { General Physicians \% } \\
\mathbf{( N = 1 0 7 )}\end{array}$ & $\begin{array}{l}\text { Pediatricians \% } \\
\mathbf{( N = 4 0 )}\end{array}$ \\
\hline Reason for consultation & 100 & 100 & 100 \\
\hline Child's age & 100 & 100 & 100 \\
\hline Pathological history & 73.9 & 90.9 & 83.3 \\
\hline Adequate weight technique & 86.6 & 96.4 & 98.3 \\
\hline Appropriate Size Technique & 86.8 & 94.5 & 98.3 \\
\hline Temperature & 41.0 & 70.4 & 55.1 \\
\hline Heart rate & 50.2 & 54.4 & 82.5 \\
\hline Breathing frequency & 63.6 & 59.9 & 79.0 \\
\hline Cephalic Perimeter & 74.7 & 68.0 & 96.0 \\
\hline
\end{tabular}

\section{- Danger signs}

Of the patients evaluated, a complete evaluation of danger signs was performed in less than $60 \%$, with the sign with the lowest evaluation being the presence or not of seizures (43.6\%), followed by the evaluation of consciousness (51.6\%). 
According to the profile of the professional, the values observed by pediatrics are higher, and do not exceed $70 \%$ in each sign. For the profile of nurse and general physician the results are similar by sign, without exceeding $65 \%$. This, except for the "vomits all" sign, which is evaluated by a general physician in $76.6 \%$ of the children assessed.

\section{- Acute diarrheal disease}

$84.3 \%$ of the health professionals asked the mother or caregiver if the child had diarrhea. In the results of the evaluation of patients with diarrhea, in general, there was high compliance in the evaluation of their characteristics, except in relation to the presence of blood in the stool.

\section{- Febrile syndrome}

Of the total number of children assessed, in $89.9 \%$ of the cases the mother, or caregiver, was asked if the child had developed a fever. Low compliance is observed in both, identifying a history of displacement to areas with dengue or malaria transmission as well as the evaluation of nuchal stiffness. According to the professional profile of general physicians and pediatricians, $100 \%$ compliance was observed in the evaluation of the duration of the fever, as well as less compliance in the evaluation of the history of visits to sites with Vector-Borne Diseases (VTE) and neck stiffness.

\section{- Otalgia}

In more than $98 \%$ of the cases, the mother or caregiver was asked if the child had ear pain. Of the total number of children assessed, $4.9 \%$ had an earache and high compliance $(98.5 \%)$ with otoscopy and behind-the-ear palpation. By professional profile, the best compliance in the evaluation of this aspect was observed in pediatrician followed by general physicians

\section{- Odynophagia}

In $78.2 \%$ of the cases, the mother or caregiver was asked if the child had developed odynophagia. In the results of the evaluation of children with odynophagia, high compliance was observed in the evaluation of tonsils and palpation of the neck in $98.5 \%$ of the cases. By professional profile, it was observed compliance of $100 \%, 99.6 \%$, and $62 \%$ in the pediatric, general physicians, and nursing profiles, respectively.

\section{- Normal Growth}

Concerning the growth evaluation, the growth curves of nutritional indicators were verified: weight for height, weight and height for age, and body mass index, as well as the identification of signs of wasting. Compliance was found to be close to $75 \%$ in these criteria. The result of the growth evaluation shows that the pediatrician performs, in more than $90 \%$ of the children evaluated, the assessment of nutritional indicators and in $85.6 \%$ the identification of signs of wasting.

In the general physician's profile, the evaluation of growth, in the parameters included in this evaluation, did not exceed $80 \%$. In $57.5 \%$ of the cases, the nurses performed the identification of these signs. 
Regarding the assessment of anemia, low compliance was observed in relation to whether the mother or caregiver was asked if the child had received iron in the last 6 months (37\%).

\section{- Development}

About development (verification in the development table and determination of the cephalic perimeter), compliance of $65 \%$ was generally observed for each of these parameters.

According to the professional profile, the highest compliance was observed in the pediatrician profile; compliance with the profile of general practitioner and nurse is similar.

\section{- Vaccination}

In $92.6 \%$ of the children evaluated, the health professionals requested the card to verify the vaccination status; In contrast, in less than $30 \%$ of the cases, the mother was told that the minor required a vaccine and when to return for its application according to the age schedule. By professional profile, the highest compliance was observed in the evaluation parameter of the vaccination scheme by verification of the card in the nursing profile. In the same way, In the profile of the physician and the pediatrician, a high degree of compliance was evidenced regarding this parameter (Table 3).

Table 3

Percentage of evaluation of topics regarding vaccination

\begin{tabular}{|c|c|c|c|}
\hline & $\begin{array}{l}\text { Nurses } \\
\% \\
(\mathrm{~N}= \\
42)\end{array}$ & $\begin{array}{l}\text { General } \\
\text { Physicians } \\
\% \\
(\mathrm{~N}=107)\end{array}$ & $\begin{array}{l}\text { Pediatricians } \\
\% \\
(\mathrm{~N}=40)\end{array}$ \\
\hline $\begin{array}{l}\text { Ask for the vaccination card and check the vaccination } \\
\text { status }\end{array}$ & 100 & 86.2 & 95.9 \\
\hline $\begin{array}{l}\text { Indicates to the mother that the child requires a } \\
\text { vaccination }\end{array}$ & 19.2 & 0.6 & 12.9 \\
\hline $\begin{array}{l}\text { Indicates to the mother on what date she should bring the } \\
\text { child back for the next vaccination }\end{array}$ & 31.5 & 20 & 14 \\
\hline
\end{tabular}

\section{- Malignancy}

In general, high compliance was observed in 6 of the 11 parameters evaluated. In the other 4 parameters (inquire for headache and bone pain, loss of appetite, fatigue, and the evaluation of lymph nodes and neurological symptoms), compliance with less than $10 \%$ of the children evaluated was observed. Eight of the eleven parameters were evaluated by $100 \%$ of the pediatricians, while the general practitioner and nurse show less compliance (Table 4). 
Table 4

Malignancy Screening Percentage

\begin{tabular}{|llll|}
\hline & $\begin{array}{l}\text { Nurses } \\
\%\end{array}$ & $\begin{array}{l}\text { General } \\
\text { Physicians } \\
\%\end{array}$ & $\begin{array}{l}\text { Pediatricians } \\
\text { \% }\end{array}$ \\
& $\begin{array}{l}\mathbf{4 2}) \\
(\mathbf{N}=107)\end{array}$ & $\mathbf{( N = 4 0 )}$ \\
\hline Ask about fever / sweating for more than 7 days & 98.8 & 39.2 & 10.9 \\
\hline $\begin{array}{l}\text { Ask about a headache that has been increasing, if you wake } \\
\text { up at night, if it is accompanied by vomiting }\end{array}$ & 0 & 28.6 & 47.9 \\
\hline Ask about bone pain in the last month & 0 & 4.3 & 47.9 \\
\hline $\begin{array}{l}\text { Ask about loss of appetite, weight, or fatigue in the past 3 } \\
\text { months }\end{array}$ & 2.3 & 67.2 & 100 \\
\hline Evaluate the child's skin & 99.4 & 95,7 & 100 \\
\hline Watch the eyes & 99.4 & 60 & 100 \\
\hline Evaluate the nodes & 2.3 & 60 & 100 \\
\hline $\begin{array}{l}\text { Evaluates focal, acute, or progressive neurological signs } \\
\text { and symptoms }\end{array}$ & 2.3 & 35.7 & 100 \\
\hline Ask about vision disturbance & 95.9 & $24 . .3$ & 100 \\
\hline Palpate the abdomen & 99.4 & 91.8 & 100 \\
\hline Scan the body to identify possible masses & 99.4 & 95.7 & 100 \\
\hline
\end{tabular}

- Tuberculosis and HIV

This evaluation was carried out in less than $20 \%$ of the children evaluated, being the lowest tuberculosis investigation, only carried out in less than $1 \%$ of the cases. Pediatricians were the ones who most met these evaluation criteria, while in no case did the nurse.

\section{- Classify Competition}

In general, the classification of signs of very serious illness and the main prevalent illnesses (cough, diarrhea, fever, and ear problems) is done correctly in more than $60 \%$ of cases. The possibility of abuse, development, and nutritional status were correctly classified in more than $70 \%$ of the children evaluated; breastfeeding, hearing, and anemia problems were correctly assessed in less than $50 \%$ of the cases.

\section{- Competence Treat}

The definition of appropriate treatment was made as included and indicated in the $\mathrm{IMCl}$ procedure chart. The treatment was only evaluated in the pediatrician and general practitioner profiles. Concerning the management of diarrhea and sore throat, $100 \%$ of the children classified correctly received adequate management. For fever, $59.5 \%$ of the cases classified correctly were managed. In general, it was observed 
that health professionals gave adequate treatment to a higher percentage of children classified correctly (Table 5).

Table 5

Proper Treatment and Correct Classification of signs and Symptoms

\begin{tabular}{|c|c|c|c|}
\hline & & \multicolumn{2}{|c|}{ Proper treatment } \\
\hline & & Yes & No \\
\hline \multirow[t]{2}{*}{$\begin{array}{l}\text { Correct classification Signs Cough and Shortness of } \\
\text { breath }\end{array}$} & $\begin{array}{l}\text { Yes }(N= \\
145)\end{array}$ & $65(44.9 \%)$ & $\begin{array}{l}80 \\
(55.1 \%)\end{array}$ \\
\hline & No $(\mathrm{N}=52)$ & $6(12.2 \%)$ & $\begin{array}{l}46 \\
(87.8 \%)\end{array}$ \\
\hline \multirow[t]{2}{*}{ Correct classification Signs Diarrhea } & $\begin{array}{l}\text { Yes }(N= \\
140)\end{array}$ & $\begin{array}{l}140 \\
(100 \%)\end{array}$ & $0(0 \%)$ \\
\hline & No $(\mathrm{N}=52)$ & $24(46.2 \%)$ & $\begin{array}{l}28 \\
(53.8 \%)\end{array}$ \\
\hline \multirow[t]{2}{*}{ Correct classification Signs Fever } & $\begin{array}{l}\text { Yes }(N= \\
147)\end{array}$ & $\begin{array}{l}147 \\
(100 \%)\end{array}$ & $0(0 \%)$ \\
\hline & No $(N=54)$ & $32(59.5 \%)$ & $\begin{array}{l}22 \\
(40.5 \%)\end{array}$ \\
\hline \multirow[t]{2}{*}{ Correct classification Throat problem } & $\begin{array}{l}\text { Yes }(N= \\
152)\end{array}$ & $\begin{array}{l}152 \\
(100 \%)\end{array}$ & $0(0 \%)$ \\
\hline & No $(N=71)$ & 0 & 71 (100\%) \\
\hline
\end{tabular}

\section{Discussion}

This study has a pioneering character in Colombia since there are no previous evaluations on the effectiveness or impact in the fulfillment of the three objectives of the IMCl strategy. Due to some limitations in the characteristics of the study design, the results found cannot be generalizable. Although they constitute a valuable contribution as a first approximation to this topic in the national scenario, some weaknesses are evident, since it may contain a certain degree of imprecision this is probably due to the random error by the sample size.

Existing studies in other countries such as Peru, Bolivia, Ecuador, assessed the experiences of the implementation of the IMCl Strategy its weaknesses and strengths in terms of administration $(10,11)$. Similarly, they estimated the impact on very specific topics such as Pneumonia, but none assesses the comprehensive results of the strategy on health personnel and the implementation of the strategy in their daily practice (12).

In terms of external validity, other countries have conducted performance studies of health workers. In the study "Assessing the IMCI performance of health workers in KENYA 2000", it is found that despite having 
a more complete evaluation through the $\mathrm{IMCl}$ strategy, a correct diagnosis is not made so that only $60 \%$ of the sick children received adequate treatment (13).

A similar evaluation carried out in South Africa in 2009 on 1325 health workers also showed low compliance ratios: (12\%) Observed health workers checked for signs of general danger in each child and only $18 \%$ evaluated all the major symptoms of danger in children. Likewise, in each child, $46.8 \%$ of cases were classified correctly. These values are lower than those evidenced in the present study (14).

The unavailability of drugs and supplies has been identified in other studies as major difficulties in carrying out IMCl according to health workers with $82 \%$ (14). Although this cause was not addressed in our study, the indicated long consultation times may be indicating institutional deficiencies in the planning of outpatient, emergency, and in general the care model.

We firmly believe that there is a need to promote new studies that delve into this topic using wider samples, designs that involve monitoring over time (Community interventions), protocols of information collection, and evaluation of multiple care centers to improve the $\mathrm{IMCl}$ strategy in our context.

\section{Conclusions}

In general, pediatricians performed better in children aged 2 months to 5 years, which may be due not only to their expertise but also to the increased frequency of evaluation of cases of children who already have prevalent morbidity on the part of these professionals. However, it is worth noting that in the age group of 0 to 2 months, the pediatricians were surpassed by general medicine and nursing. In the areas of prevention such as vaccination, breastfeeding, and child development assessment, the performance of nurses is very adequate. There are still difficulties in accurately classifying and treating children with prevalent childhood illnesses, so the way in which clinical IMCI is taught should be reconsidered.

In the municipalities surveyed, a care model was presented in most places. This means that children have access to health services not from everyday life, but through outpatient, emergency, and hospitalization services. This causes the professionals to use different evaluation criteria of AIEPI or event guides such as Acute Respiratory Infection or Acute Diarrheal Disease.

The use of strategy questions by valued professionals may influence your evaluation of IMCl. Usually, the algorithm used by $\mathrm{IMCl}$ is serial testing, however, professionals may be using them in parallel. This implies the need to modify in the future the instruments and methodology of observation, since the professional may be doing simultaneous tests and not in the sequence expected by the observer.

\section{Abbreviations}

SIGIT Research Line: Health Systems, Infants, Gender, Interculturality and the Tropics (by acronym in Spanish) 
HPIs: Health Provider Institutions

ASIS: Health Situation Analysis (by acronym in Spanish)

ARI: Acute Respiratory Infection

ADD: Acute Diarrheal Disease

HIV: Human Immunodeficiency Virus

VTE: Vector-Borne Diseases

\section{Declarations}

\section{Ethical Approval and Consent to Participate}

The study was conducted in accordance with the Declaration of Helsinki and was approved by the research ethics committees of the Universidad de los Andes, in Colombia, and the Pan American Health Organization, which classified it as minimal risk research. Informed consent was obtained from the health professionals who participated in this study.

\section{Consent for publication}

This section does not apply.

\section{Availability of data and materials}

The datasets generated and/or analyzed during the current study are not publicly available due to, the informed consent signed by health professionals prohibited sharing information but are available from the corresponding author on reasonable request

\section{Competing interest}

The authors declare that there is no conflict of interest

\section{Funding}

This work was supported by the Pan American Health Organization (PAHO) (Contract Number SCON2016-00711)

\section{Author's contributions}

JAOC and AMGS had the research idea and the conception of the work, designed the work, analyzed the information, and interpreted the analyzes. YYPM, DSRO, and AJAG recollected the information and analyzed the information. LJHF participated in the analyzes of the information. JSPR wrote the article and translate to English. All authors approved the final manuscript. 


\section{References}

1. Ministerio de Salud y Protección Social de Colombia. Análisis de Situación de Salud (ASIS) 2019. 2019;264. Available from:

https://www.minsalud.gov.co/salud/publica/epidemiologia/Paginas/analisis-de-situacion-desalud-.aspx

2. Organización Panamericana de la Salud, Organización Mundial de la Salud. Plan de Acción para la Salud de la Mujer, El Niño, La Niña y Adolescentes [Internet]. 2018. Available from: https://iris. paho.org/bitstream/handle/10665.2/49609/CD56-8-es. pdf?sequence=15\&isAllowed=y

3. Sanahuja JA. De los Objetivos del Milenio al desarrollo sostenible: Naciones Unidas y las metas globales post-2015. 2015;49-83.

4. Organización Mundial de la Salud. Estrategia Mundial Para la Salud de la Mujer, El Niño y El Adolescente (2016-2030). 2016.

5. Camargo-Ramos CM, Pinzón-Villate GY. La promoción de la salud en la primera infancia: evolución del concepto y su aplicación en el contexto internacional y nacional. 2012;60:62-74.

6. Rios-Oliveros DS. Diseño, Implementación y Aproximación de una Estrategia de Aprendizaje Blended Learning en la Enseñanza del Curzo Atención Integrada a las Enfermedades Prevalentes de la Infancia (AIEPI), Dirigido a Profesionales de la Salud, Bogotá, Colombia 2015 [Internet]. Universidad de los Andes; 2015. Available from:

https://repositorio.uniandes.edu.co/bitstream/handle/1992/13804/u729387.pdf?

sequence $=1$ \&isAllowed $=y$

7. Lamus F, Rosa L, Durán M, Docal C, Luz M, Soto A, et al. Construcción de un modelo de gestión para la salud y el bienestar de la infancia en la implementación de la estrategia aiepi en Colombia. 2007;6(12):126-43.

8. Figueiras AC, Neves de Souza IC, Rios VG, Benguigui Y, Organizacion Panamericana de la Salud. Manual para la Vigilancia del Desarrollo Infantil en el Contexto de AIEPI [Internet]. Washington; 2006. 55 p. Available from: https://www.paho.org/spanish/ad/fch/ca/si-desarrollo1.pdf

9. Ministerio de Salud y Protección Social de Colombia, Organizacion Panamericana de la Salud. Guía para la Atención y la Consejería de la Niñez en la Familia [Internet]. Bogotá; 2010. 118 p. Available from: https://www.minsalud.gov.co/sites/rid/Lists/BibliotecaDigital/RIDE/DE/GUIA-PARA-LAATENCION-DE-LA-NINEZ-EN-LA-FAMILIA.pdf

10. Quizhpe A, Uphoff E, Encalada L, Andrade D, Barten F. Aplicación de la estrategia de Atención Integral de Enfermedades Prevalentes de la Infancia en Ecuador. Rev Cuba Salud Publica. 2013;39(2):197207.

11. Zamora G AD, Cordero V. D, Mejia S. M. Evaluación de la estrategia \&quot;Atención integrada a las enfermedades prevalentes de la infancia\&quot; (AIEPI) en Servicios de Salud, Bolivia 1999. Rev Chil pediatría [Internet]. 2002 Mar [cited 2020 Nov 18];73(2):184-91. Available from: 
http://www.scielo.cl/scielo.php?script=sci_arttext\&pid=S0370-

41062002000200014\&lng=en\&nrm=iso\&tlng=en

12. Pinzón Gómez EM, Moran Garreta LM, Loboa Arboleda N,, Cedeño Macías , Paula Andrea. Manejo clínico de pacientes menores de 5 años hospitalizados con diagnóstico de neumonía acorde con la estrategia AIEPI, en una institución de salud, Cauca, Colombia. Rev Colomb Salud Libr. 2015;10(2):116-23.

13. Ya-Shin Lin; Paula Tavrow. Evaluación del desempeño en AIEPI de los trabajadores de salud en Kenya. 2000;13.

14. Horwood C, Vermaak K, Rollins N, Haskins L, Nkosi P, Qazi S. An evaluation of the quality of IMCI assessments among IMCI trained health workers in South Africa. PLoS One. 2009;4(6). 